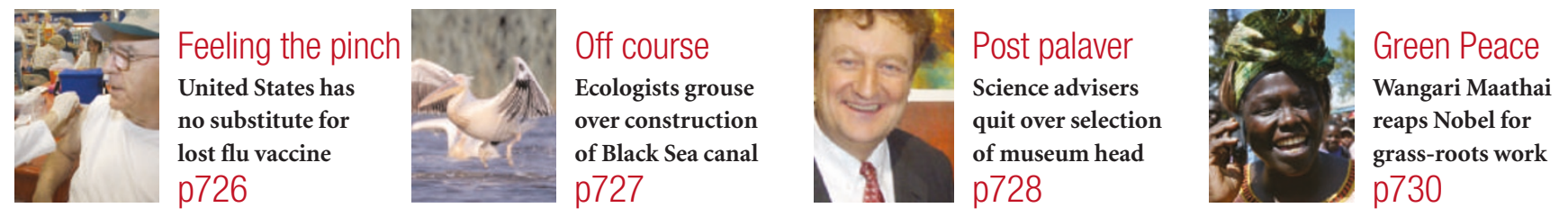

\title{
Universities fear repercussions as NIH tunes conflicts policy
}

\section{Erika Check, Washington}

A high-profile investigation into conflict-ofinterest policies at the National Institutes of Health (NIH) is having an impact way beyond Washington, as universities around the United States work out how it might affect their medical research centres.

So far, the congressional investigation has focused on policies governing the conduct of the 6,000 intramural scientists who work directly for the agency, mostly at its main campus in the Washington suburb of Bethesda, Maryland.

And investigators have not publicly announced that they plan to extend the investigation to university medical centres, where 200,000 scientists at all levels are supported by almost $\$ 20$ billion in annual funding from the $\mathrm{NIH}$ (see chart). But an official at the agency, who did not want to be named, says that questions about the universities' conflict-ofinterest policies have already been raised by the investigators. And campus officials are tracking the subject closely, because Congress is clearly concerned about the issue and $\mathrm{NIH}$ policy changes are likely to affect universities, directly or indirectly.

"It matters that Congress is taking an interest," says Julie Gottlieb, assistant dean for policy coordination at the Johns Hopkins University School of Medicine in Baltimore, Maryland. "It will result in changes at NIH, and it may signal changes for NIH grantee institutions."

The agency has already said it will change its own policies, requiring more disclosure and reducing the amount of paid consulting that its senior scientists are permitted to do. It is also planning to enact a one-year moratorium on paid consulting for all of its scientists (see Nature 431, 497; 2004).

This moratorium is more drastic than any measure a university is likely to contemplate. Still, such changes could affect universities in many ways. When the NIH's rules

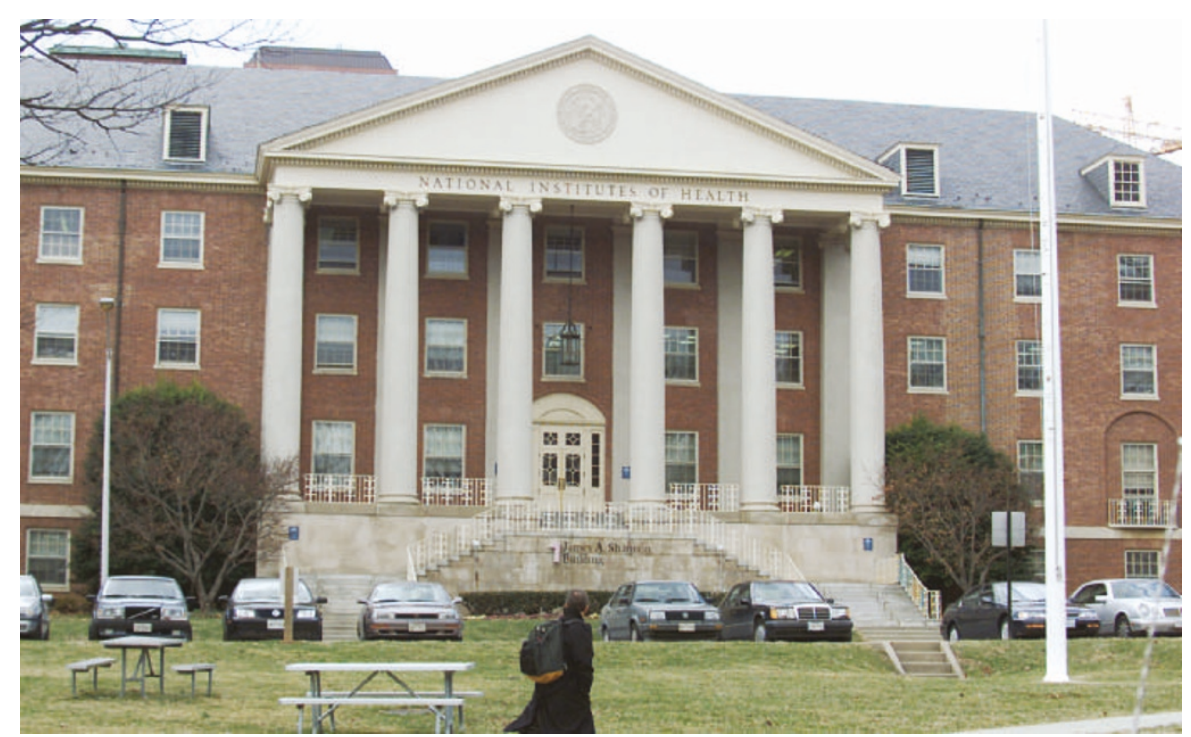

Side-effects: revisions to the National Institutes of Health's conflict-of-interest policy could affect conditions on the outside grants that account for three-quarters of the agency's spending. on conflicts of interest are finalized, for example, the agency could decide to create new rules for grantees. Or universities could choose to follow the lead and adopt rules that are more in line with those of the agency.

"When you see the body responsible for regulation changing its own rules, you have to look at its changes," says Theresa Colecchia, associate general counsel at the University of Pittsburgh. "It can be an indication of where those grant-funding agencies will go with regulations for grant recipients in the future."

\section{Policies strengthened}

According to a survey released last month by the Association of American Medical Colleges (AAMC), most medical schools have adopted conflict-of-interest policies for faculty involved in human research. And $63 \%$ of these schools have strengthened their policies since 2001. Although the Public Health Service, the division of the federal health department that includes the NIH, issues broad guidelines for these policies, the specifics vary across universities.

For instance, $40 \%$ of medical schools surveyed by the AAMC do not require faculty members to disclose potential financial conflicts in verbal presentations. Three-quarters of the schools have set up standing committees to evaluate conflicts of interest, but only $21 \%$ of these schools require community representation on the committee. And just slightly more than half of the schools surveyed require the standing committees to review technology-licensing agreements that may influence future research undertaken by individual faculty members.

Most university officials say that the policies at their own institutions are sound and that they are not planning alterations. "We have one of the broadest conflict-ofinterest policies of any institution," says Barbara Flynn, manager of the conflict-ofinterest review programme at Stanford University School of Medicine in California. "I don't think there's anything more we can do."

For the moment, US universities are not in line for a direct grilling by Congress: staff members on the committee leading the NIH investigation say they do not plan to spread their net to campuses. But university officials will not rest easy until the investigation ends, and the NIH rules are set. 